Claves. Revista de Historia, Vol. $4, \mathrm{~N}^{\circ} .6$

Montevideo, enero- junio 2018

(pp. 9 - 42) ISSN 2393-6584

\title{
Compadres de una misma frontera. El compadrazgo en los curatos de Alegrete, Belén y Paysandú en la primera mitad del siglo XIX
}

Godfathers in the same frontier. The patronage in the parishes of Alegrete, Belén and Paysandú in the first half of the 19th century

Andrés O. Azpiroz Perera

Universidad de la República Museo Histórico Nacional, Uruguay

Luís A. Farinatti

Recibido: 18/03/2018

Aceptado: 21/04/2018

Resumen: El artículo examina las características del compadrazgo en la frontera entre la Banda/ Provincia/ Estado Oriental con la provincia de Rio Grande del Sur, en la primera mitad del siglo XIX. La comunicación focaliza el estudio de esa práctica social en las parroquias fronterizas de Alegrete, Belén y Paysandú, considerando ese espacio como una misma frontera. El objetivo es poner de manifiesto la conformación de redes sociales a partir de esa forma de "parentesco espiritual" y reflexionar sobre las ventajas de su análisis para el conocimiento de esas poblaciones y la conformación de liderazgos locales.

Palabras clave: frontera, compadrazgo, liderazgos.

\begin{abstract}
The article examines the characteristics of patronage on the border between the Banda/ Provincia/ Estado Oriental (territory of the eastern bank of the Uruguay River) and the province of Rio Grande do Sul, in the first half of the 19th century. The communication focuses on the study of this social practice in the border parishes of Alegrete, Belén and Paysandú, considering this space as the same border. The objective is to outline the formation of social networks based on this form of "spiritual kinship" and reflect on the advantages of their analysis for the knowledge of these populations and the formation of local leaderships.
\end{abstract}

Keywords: border, patronage, leaderships. 
Tal como lo ha señalado el historiador francés Maurice Agulhon, la "sociabilidad" se ha convertido en una categoría de análisis histórico que interpela la capacidad de los hombres y las mujeres de vivir en sociedad y estrechar relaciones. Según el autor, "todo grupo humano, ya se lo defina en el espacio, en el tiempo o en la jerarquía social, posee su sociabilidad, en cierto modo por definición, cuyas formas específicas es conveniente analizar". La sociabilidad supone el acuerdo en normas y reglas concretas que permiten sostener las relaciones sociales en el tiempo. El compadrazgo es la afinidad que contraen los padres con los padrinos y madrinas luego del bautismo. Esta forma de "contrato" se forja en la pila bautismal, cuando nace un "parentesco espiritual" entre ellos.

La relación entre padrinos, ahijados y padres puede ser además la llave para conseguir favores, afirmar los vínculos de parentesco filial, fortalecer relaciones previas con cuñados o familiares cercanos o extender el "alcance" de la familia a otras por las que no se está unido de forma sanguínea.

Teniendo en cuenta estos aspectos, el artículo analiza la cuestión del compadrazgo en las parroquias de Belén y Paysandú del Estado Oriental y la parroquia de Alegrete en la provincia de Río Grande del Sur. El lector advertirá que mientras en el caso de la parroquia riograndense aparecen comparaciones con otras situaciones en Brasil, para el Estado Oriental no se cuentan con antecedentes sobre el estudio del compadrazgo como los aquí propuestos.

En la primera parte del artículo se presentan los estudios de compadrazgo y sus vínculos con la historia social. En los apartados siguientes, el análisis se detiene en las características concretas del compadrazgo en las parroquias fronterizas de Belén, Paysandú y Alegrete. En ese sentido, se estudian a aquellos padrinos que concentraron más ahijados en el período investigado. El análisis avanza sobre todo en la constatación de la existencia de alianzas y redes sociales que permiten acercarse a las elites locales desde la reflexión sobre esta forma particular de relación social.

\footnotetext{
${ }^{1}$ Maurice Agulhon citado en GONZÁLEZ BERNALDO DE QUIRÓS, Pilar, "La 'sociabilidad' y la historia política”, en Nuevo mundo. Mundos nuevos [en línea], 17 de febrero de 2008. Disponible en https://nuevomundo.revues.org/24082\#tocto1n1
} 


\section{El estudio del compadrazgo y la historia social}

Los registros de bautismo son una fuente muy útil para los estudios históricos desde diferentes abordajes. Además de los usos tradicionales de la historia demográfica, los investigadores interesados en problemáticas ligadas a la historia social recurren a ellos de manera frecuente. En la última década en el Río de la Plata se multiplicó el empleo de los registros bautismales no solo para contrastar las características generales de una población, sino también para el estudio de modos de estratificación, alianzas sociales y construcción de liderazgos políticos. En este caso, el aspecto privilegiado ha sido el análisis del compadrazgo² .

En las sociedades de los siglos XVIII y XIX, muchos de los recursos materiales e inmateriales eran producidos, circulaban y se acumulaban a través de relaciones de reciprocidad horizontal y vertical, configuradas en alianzas de auxilio mutuo, lealtad

\footnotetext{
2 En los últimos años la cuestión del compadrazgo ha sido analizada por la historiografía del Río de la Plata. Los estudios han estado vinculados a la renovación teórico metodológica que ha avanzado en el conocimiento sobre los espacios rurales de la región. Con el objetivo de dar cuenta de este aspecto mencionamos algunos trabajos que, además de dinamizar el debate historiográfico, son de referencia para este artículo. En Argentina los historiadores José Mateo, Daniel Santilli y Juan Carlos Garavaglia han incorporado la temática a sus intereses académicos. Al respecto Cf. MATEO, José, Población, parentesco y red social en la frontera. Lobos (provincia de Buenos Aires) en el siglo XIX, Mar del Plata, UNMdP, 2001; SANTILLI, Daniel, "Representación gráfica de redes sociales. Un método de obtención y un ejemplo histórico", Mundo Agrario, vol. III, n ${ }^{\circ}$ 6, enero-junio 2003; SANTILLI, Daniel, "Entre el clientelismo y el reforzamiento de vínculos. Familia y padrinazgo en Buenos Aires, 1780-1840", en Revista de Demografía Histórica, vol. 27, $\mathrm{n}^{\circ}$ 2, 2009, pp. 111-148; GARAVAGLIA, Juan Carlos, San Antonio de Areco, 1680-188o. Un pueblo de la campaña, del Antiguo Régimen a la modernidad argentina, Buenos Aires, Prohistoria Ediciones, 2009. En Brasil, el tema ha sido estudiado por varios historiadores. Entre otros: FRAGOSO, João Luis Ribeiro, “A nobreza vive em bandos: a economia política das melhores famílias da terra do Rio de Janeiro, século XVII. Algumas notas de pesquisa”, Tempo, vol. 8, no 15, UFF, Niterói, julio-dic. 2003, pp. 11-36; KUHN, Fabio, Gente da Fronteira: família, sociedade e poder no sul da América Portuguesa - Século XVIII, Tese (doutorado em História), UFF, Niterói, 2006; HAMEISTER, Martha, Para Dar Calor à Nova Povoação: estudo sobre estratégias sociais e familiares a partir dos registros batismais da Vila do Rio Grande (1738-1863), Tese (doutorado em História Social) Instituto de Filosofía e Ciências Humanas, UFRJ, Rio de Janeiro, 2006; VENÂNCIO, Renato Pinto; SOUZA, María José Ferro; PEREIRA, María Teresa Gonçalves, "O compadre governador. Redes de compadrio em Vila Rica em fins do século XVIII", Revista Brasileira de História, vol. 26, ${ }^{\circ}$ 52, 2006, pp 273-294; BRUGGER, Silvia María, "Escolhas de padrinhos e relações de poder: uma análise do compadrio em São João d'El Rey (1736-1850)", José Murilo de CARVALHO (org.), Nação e cidadania no Império: novos horizontes, Rio de Janeiro, Civilização Brasileira, 2007, pp. 313-347; SIRTORI, Bruna, Entre a cruz, a espada, a senzala e a aldeia: hierarquias sociais em uma área periférica do Antigo Regime (17651784), Dissertação (mestrado em História Social), Instituto de Filosofia e Ciências Humanas, UFRJ, Rio de Janeiro, 2007; GUEDES, Roberto, Egressos do cativeiro. Trabalho, família, aliança $e$ mobilidade social (Porto Feliz, São Paulo, c. 1789-c.1850), Rio de Janeiro, Mauad-FAPERJ, 2008; MACHADO, Cacilda da Silva, A trama das vontades: negros, pardos e brancos na construção da hierarquia social do Brasil escravista, Rio de Janeiro, Apicuri, 2008 y de la misma autora "O Capitão João Pereira de Lemos e a parda Maria Sampaio: notas sobre as hierarquias rurais costumeiras no Rio de Janeiro do século XVIII", Monica Ribeiro OLIVEIRA y Carla María ALMEIDA (orgs.), Exercícios de micro-história, Rio de Janeiro, FGV Editora, 2009.
} 
y protección. Esos medios informales estaban a veces, combinados con las relaciones comerciales, institucionales y asociativas de los individuos. Aunque se reconozcan los límites de este tipo de estudios, el análisis del compadrazgo ha sido empleado para cartografiar parcialmente esas relaciones. Además, el padrinazgo permite reconstruir grupos sociales y de convivencia que, a veces, podían tener un sentido jerárquico y congregar personas de diferentes condiciones sociales. En todos esos casos, el estudio del compadrazgo puede aportar a la percepción de una imagen más compleja del espacio social estudiado.

Dentro de dicho contexto una de las posibilidades de análisis más empleadas ha sido el estudio de padrinos y madrinas principales. Teniendo en cuenta la costumbre muy difundida de buscar compadres y comadres en los mismos estratos sociales o en grupos jerárquicamente superiores, se ha optado por elegir el número de veces que algunos individuos eran llamados para bautizar como un indicio de su prestigio social y de las relaciones que conseguían movilizar.

Examinar la cuestión del compadrazgo significa también analizar la familia puesto que, como señala Juan Carlos Garavaglia, desde el Antiguo Régimen ocupa "un lugar central en el modo en que se configuran las relaciones sociales" 3. Por lo tanto, significa estudiar el "honor" y el "prestigio", cuestiones que "hacen a la calidad de las personas en esta sociedad" y que atraviesan "las líneas dibujadas por los lazos de parentesco". Ambos aspectos no eran exclusivos de las elites, sino que permearon toda la sociedad y entonces permiten comprender el fenómeno del compadrazgo en otros sectores sociales más allá de las notabilidades locales4.

Naturalmente, es necesario estar advertidos sobre los límites y "trampas" de este tipo de análisis. Las condiciones de producción de la documentación eran diversas y podían influenciar fuertemente el abanico de opciones que una madre o un matrimonio tenía al invitar a alguien para bautizar a sus hijos. Además, los significados del bautismo y del compadrazgo no eran exactamente los mismos para las personas situadas en diferentes posiciones del espacio social o portadores de referencias culturales diversas. Es posible imaginar que, aunque compartieran una tradición cristiana, las poblaciones criollas, lusas, guaraníes, afro-americanas, libres y

3 GARAVAGLIA, Juan Carlos, ob. cit., p. 139.

4 Ibidem, p. 165. 
esclavizadas pudieran tener concepciones diferentes sobre el significado social del compadrazgo. No obstante, aun teniendo en cuenta estas advertencias, el bautismo fue una práctica muy difundida en la primera mitad del siglo XIX en las regiones de frontera entre los nacientes Estados del sur de América. Es en ese sentido que orientamos el análisis de ahora en más.

\section{El compadrazgo en Belén y Paysandú}

El objetivo del apartado es analizar quiénes fueron los vecinos que en cada parroquia concentraron más ahijados. Además, conocer cómo se caracterizó el fenómeno del compadrazgo en el litoral del río Uruguay durante la primera mitad del siglo XIX.

Para el caso de Paysandú, se estudiaron los 2.197 bautismos realizados entre 1805 y 1830. Para la parroquia de Belén se analizaron los cuatro primeros legajos de bautismos que registran 1.010 partidas, desde 1838 a $1849^{5}$.

El registro de las fuentes se realizó en una planilla electrónica donde se discriminó por categorías toda la información contenida en las partidas de bautismo. Teniendo en cuenta estudios similares en la región, se seleccionaron aquellos padrinos y madrinas que habían sido elegidos en cuatro o más oportunidades ${ }^{6}$. Con esa información se elaboró una lista de los diez padrinos y madrinas con más ahijados de cada curato.

En todo el período analizado, Francisco María Bernaola se desempeñó como cura vicario de Belén. Bernaola anotó los nombres de padres, padrinos y bautizados, su oriundez, el lugar de residencia, el "color" del bautizado y, en algunos casos, su condición jurídica. En relación con los padres y las madres de condición esclava, casi siempre registró el nombre de los amos. Por el contrario, nunca anotó el estado jurídico de los padrinos, por lo que conocer el padrinazgo de los afrodescendientes en su parroquia es una tarea por ahora difícil de resolver. A diferencia de lo que ocurrió

\footnotetext{
${ }^{5}$ Los extremos cronológicos se refieren a las fuentes disponibles para esta investigación. En el caso del primer libro de Bautismos de Belén, la base de datos que aquí se refiere fue realizada por Andrés Azpiroz e Isabel Barreto.

6 FARINATTI, Luís Augusto; MATHEUS, Marcelo Santos, "Sobre Angélica, José Maria e Jacinto: hierarquia social e padrinhos/madrinhas preferenciais escravos no sul do Brasil (1817-1845)", Maíra Ines VENDRAME; Alexander KARSBURG y otros (orgs.), Micro-história, trajetórias e imigraçāo, Sāo Leopoldo, Oikos, 2015, pp. 99-121.
} 
en otros sitios de la región, los curas de la frontera del litoral del Uruguay no llevaron libros separados para indios o afrodescendientes.

Entre 1838 y 1849, el cura de Belén realizó 1.010 bautismos donde los padres declararon ser vecinos de distintos parajes. Llama la atención que recién a partir de 1848 haya registros de padres y padrinos de la villa de Belén. Las consecuencias de las guerras en la región fueron uno de los motivos. El 17 de enero de 1840, tropas que recibían órdenes de Manuel Oribe, el gobernador de Santa Fe, Juan Pablo López, Juan Antonio Lavalleja y Servando Gómez arremetieron contra una escuadrilla subordinada al gobierno de Montevideo que estaba frente a la villa. Además de destruir las naves, Belén fue saqueado y devastado, destruyéndose buena parte de los ranchos del pueblo7. Es probable que por las consecuencias de la guerra y las distintas acciones violentas sobre la población muchos hayan optado por residir en la campaña, en zonas cercanas como la Sierra (14\%), de donde la mayoría declaró ser vecino, o sobre los ríos Cuareim, Cuaró o Arapey. Esta información es corroborada unos años más tarde por el viajero y naturalista francés Martín de Moussy, quien caracterizó la villa de Belén y la de Bella Unión como "pobres aldeas con tres o cuatro pulperías y una docena de ranchos; algunas chacharitas [sic] donde se cultiva el maíz y la mandioca, unos pocos durazneros e higueras son las únicas señales de cultivo que se ve"

Para Bernaola, el tema de las jurisdicciones eclesiásticas no estaba saldado; además, la inexistencia de límites entre Brasil y el Estado Oriental podía ser un factor a su favor. La constatación de los diversos orígenes de los fieles de la parroquia comprueba este aspecto. El $13 \%$ declaró ser vecino de Brasil, probablemente en zonas de jurisdicción de la parroquia de Alegrete. De hecho, de la lectura del libro se advierte cómo el sacerdote salía de recorrida por distintas zonas de su curato y se adentraba en Brasil bautizando hasta las proximidades del río Ibicuy.

La referencia a los distintos lugares donde padres y padrinos declaraban ser vecinos da cuenta de la dispersión de la población en ese espacio y de la presencia de pequeños caseríos más allá de los pueblos establecidos formalmente. Algunos de

\footnotetext{
7 BARRIOS PINTOS, Aníbal, Historia de los Pueblos orientales, Montevideo, Ediciones de la Banda Oriental y Ediciones Cruz del Sur, 2008, Tomo II, p. 296.

8 DE MOUSSY, Martín, "Notas de viaje por el río Uruguay", Revista Histórica, Tomo LV, año LXXXIV, $\mathrm{n}^{0}$ 164-165, Montevideo, diciembre de 1991, p. 537.
} 
estos asentamientos fueron lugar de campamentos militares, como el sitio del Arapey9, se consolidaron como pequeños pueblos a fines del siglo XIX como Arerunguá10, Yaguarí11 y Cuaró ${ }^{12}$ o funcionaron como puerto como el caserío del Cuareim ${ }^{13}$.

El registro bautismal permite advertir la dispersión de los vecinos en torno a la villa de Belén. La bibliografía ha señalado en reiteradas ocasiones que el Estado Oriental al norte del río Negro estaba habitado principalmente por familias procedentes de Brasil. Los datos surgidos a partir del libro de bautismos confirman que la mitad de los padres, feligreses del curato de Belén, declararon ser oriundos de Brasil. Entre ellos, casi un 80 \% señaló ser vecino de Río Grande del Sur. Al mismo tiempo, las localidades de Cachoeira y Río Pardo fueron señaladas como los sitios principales de origen de los padres. Al tránsito de los vecinos en un área de frontera puede sumarse como otra de las razones la circunstancia del establecimiento del campamaneto lusitano en 1821, cuando las milicias de río Pardo se instalaron en esa frontera ${ }^{14}$.

Entre los padres del Estado Oriental, casi la mitad de ellos fueron registrados como oriundos de la Sierra, paraje cercano a la villa que, como ya se mencionó, era uno de los sitios más poblados de la zona. La otra mitad era natural del Estado Oriental, sin registrarse el lugar específico.

A partir de 1848 las cercanías de Belén se convirtieron en escenario de guerra. Por casi dos años el cura Bernaola incorporó en sus registros la categoría de "vecinos volantes" para nombrar a quienes por la llamada Guerra Grande o guerra contra Rosas residían en Belén. Muchos de ellos integraban el ejército, detalle que se conoce por la anotación al margen de las partidas. En ese período se multiplicó la presencia de familias oriundas de Buenos Aires, sitio principal entre los declarados por los recién llegados a la villa. Seguramente su presencia alteró la vida pueblerina, pues en varios casos se conoce a través del bautismo de sus hijos que permanecieron allí por

9ARAÚJO, Orestes, Diccionario Geográfico del Uruguay, Montevideo, Moderna, 1912, pp. 24-25.

${ }^{10}$ Ibidem, p. 32.

${ }^{11}$ Ibidem, p. 525.

12 Ibidem, p. 151.

13 Ibidem, pp. 146-150.

14 SAINT HILAIRE, Auguste, Al sur del Brasil, al norte del Río de la Plata, Montevideo. Udelar, 2005, p. 203. 
lo menos por un año. Así fue el caso de Juan Pedro Fruto, anotado como "militar" y su compañera Mercedes Silva, él oriundo de Buenos Aires y ella de Corrientes, quienes bautizaron sin otorgarle padrinos a su hija Sebera del Carmen en enero de 1848. En diciembre del año siguiente bautizaron a su hija María Felicia y optaron como padrinos por una pareja de "vecinos volantes" también establecidos en la villa ${ }^{15}$.

La presencia de europeos era ínfima: apenas fueron registrados tres vecinos de Canarias, dos "alemanes" y un "español". Por otra parte, el registro de padres de origen misionero es muy bajo: solo el $3 \%$. Paysandú, como antiguo "pueblo de indios", representaba un destino principal en la zona para los originarios de los pueblos de Misiones. De todas formas, es posible que exista un subregistro o que esos vecinos ya se consideraran del lugar por haber poblado durante años o ser descendientes de guaraníes de las misiones que arribaron antes a la zona. Veinte años atrás, el naturalista Saint Hilaire había constatado la movilidad de aquellos en la zona, donde quedaban solo "algunos ancianos e inválidos que eran completamente incapaces de desplazarse". Al mismo tiempo, el naturalista señaló cómo desde "el mes de agosto del año pasado [1820] más de tres mil de estos pobres infelices han atravesado el río Uruguay" y afirmaba enseguida que "entre los que se quedaron en Belén, los hombres trabajan como peones en los campos de las cercanías, algunos niños sirven a los oficiales o incluso a los soldados del campamento y las mujeres se prostituyen"16.

\section{El padrinazgo en el curato de Belén}

En Belén, apenas siete padrinos reunieron más de cuatro ahijados. El padrino que concentró más ahijados fue elegido en ocho ocasiones, los seis restantes lo hicieron en cuatro oportunidades. En cuanto a las madrinas, nueve de ellas tuvieron más de cuatro ahijados. La mujer que reunió más ahijados tuvo ocho.

Aunque son cifras modestas, hay tres aspectos que se pueden mencionar. Por un lado, el potencial de este tipo de análisis cuando se estudian períodos más extensos: en el caso de Belén apenas son nueve años, mientras que en Paysandú se trata del registro de veinticinco años. En segundo lugar, las dificultades para el análisis derivadas de la falta de registro de los apellidos de las madrinas. El cura

\footnotetext{
15 Uruguay, Archivo Curia Eclesiástica de Salto (en adelante ACES), Legajos de Bautismos de la Parroquia de Nuestra Señora de Belén, f. 22v.

${ }^{16}$ SAINT HILAIRE, Auguste, ob. cit., p. 205.
} 
vicario de Belén no anotó en reiteradas ocasiones sus apellidos, por lo que es aventurado estudiar el fenómeno contando solamente con los nombres de pila. Por último, no es posible estudiar la condición jurídica de padrinos y madrinas por no haberse registrado.

Entre los padrinos de Belén, Juan Carballo fue quien alcanzó el mayor número de ahijados. Carballo reunió ocho ahijados entre 1844 y 1845. Entre ellos estaban Lugeria y Brígida, ambas anotadas como "hija oculta de María, esclava de Constantina Techera”. En las dos ocasiones, Techera fue la madrina ${ }^{17}$.

Lamentablemente se desconoce cuáles eran las condiciones que reunía Carballo para ser elegido como padrino. La posesión de tierras, la propiedad de un negocio rentable, el ejercicio de las "armas", la "cruz" o la justicia eran méritos suficientes. En la lista de padrinos de Belén, aunque reunieron apenas tres ahijados cada uno, aparecen los nombres del cura Bernaola y de Diego Lamas. En 1842, luego de la batalla de Arroyo Grande, Diego Lamas revistó en el Ejército Unido de Vanguardia de la Confederación Argentina. En 1845 asumió como jefe de fronteras de Tacuarembó y Cuareim y enseguida fue promovido como comandante de la frontera de Brasil y ascendido a coronel18. Durante todo ese tiempo permaneció en el litoral y entre 1848 y 1849 , en jurisdicción de esta parroquia fue elegido padrino en tres ocasiones ${ }^{19}$.

También aparecen casos donde los soldados piden a sus superiores que oficien de padrinos de sus hijos. En una sociedad como la del Río de la Plata, que se vio movilizada en armas durante varias décadas, la carrera militar ocupaba un lugar de privilegio. Así, no es extraño que una pareja de "vecinos volantes" haya elegido en mayo de 1848 a dos padrinos para sus hijos: el coronel Manuel La Balle y el capitán Tomás Blanco, ambos "vecinos volantes" ${ }^{20}$. Sin importar las dimensiones del curato, su cantidad de habitantes o su extensión geográfica siempre se trataba de personas que gozaban de prestigio en esa comunidad.

\footnotetext{
17 Uruguay, ACES, Legajo de Bautismos $n^{0} 1$ de la Parroquia de Nuestra Señora de Belén, f. 44v.

18 FERNÁNDEZ SALDAÑA, José María, Diccionario Uruguayo de biografías 1810-1940, Montevideo, Adolfo Linardi, 1945, p. 690.

19 Uruguay, ACES, Legajo de Bautismos $n^{0} 4$ de la Parroquia de Nuestra Señora de Belén, f. 20v.

20 Uruguay, ACES, Legajo de Bautismos $n^{0} 2$ de la Parroquia de Nuestra Señora de Belén, $20 \mathrm{v}$.
} 
Alcanza con leer algunas partidas de bautismo de Belén para constatar que en reiteradas ocasiones el origen de los padrinos es distinto al de los padres, incluso unos pueden ser vecinos del Estado Oriental y otros de algún pueblo brasileño cercano. En un ámbito fronterizo el mantener relaciones de compadrazgo de los dos lados de la frontera fue una ventaja para algunas familias. Entre quienes abrazaron la carrera de las armas, el compadrazgo fue una posibilidad de estrechar vínculos o cimentar alianzas entre jefes militares.

En 1842, Joaquina Correa, oriunda de Brasil, vivía junto con su esposo Pablo Martines, vecino de Entre Ríos, y sus hijas Cándida y María Lauriana en la costa del arroyo Pintado. Para su segunda hija anotaron como madrina a "Nuestra Señora de la virgen”21. Seis años más tarde se radicaron en la villa de Belén, donde nació María Luisa. Joaquina fue madrina en ocho ocasiones, en tres compartió el ahijado con su esposo y una vez lo hizo con el cura vicario de Belén. Sus ahijados eran "blancos", aunque en el bautismo de un niño en 1842 la madre figura como guaraní. Como ha sido analizado para otros puntos de la frontera y en particular entre los esclavizados, es probable que ser ahijado de Joaquina representara una ventaja que el curaempadronador expresó en el "blanqueamiento"22.

Paula Marques, una "vecina volante" en Belén, fue madrina en siete ocasiones en solo dieciocho meses, entre abril de 1848 y setiembre del año siguiente. En mayo de 1848 , frente a la ausencia de la madrina elegida por dos "vecinos volantes" para su hijo, actuó en procuración de Encarnación Camirniaga, hermana del alférez Juan Camirniaga, quien era el padrino 23 . Paula fue la madrina de los tres ahijados de Diego Lamas y de uno de su hermano Alfonso. En dos de los casos los padres aparecen registrados como militares, por lo que es probable que pertenecieran a las fuerzas de

\footnotetext{
${ }^{21}$ Uruguay, ACES, Legajo de Bautismos $n^{0} 1$ de la Parroquia de Nuestra Señora de Belén, f. 29. El proponer a la virgen María como madrina aparece referido también en el bautismo de Manuel, oriundo de Brasil en 1849. En ambos casos se trata de hijos legítimos, anotados como "blancos". Como señala José Mateo, en algunos ámbitos rurales los hijos naturales fueron puestos bajo la protección de la virgen María como su madrina. Al respecto Cf. MATEO, José, "Bastardos y concubinas. La ilegitimidad conyugal y filial en la frontera bonaerense (Lobos 1810-1869)", Boletín del Instituto de Historia Argentina y Americana "Dr. Emilio Ravignani", Tercera serie, ${ }^{\circ}{ }_{13}^{13}$, primer semestre de 1996, p. 13.

${ }^{22}$ FARINATTI, Luís Augusto; MATHEUS, Marcelo Santos, ob. cit.

23 Uruguay, ACES, Legajo de Bautismos $n^{0} 2$ de la Parroquia de Nuestra Señora de Belén, f. 24.
} 
la Confederación Argentina comandadas por Lamas. Una situación semejante es la de Matilde Viera, una vecina de Belén, quien fue elegida madrina en cinco ocasiones²4.

Estas mujeres reunían alguna cualidad singular que les otorgaba prestigio para ser preferidas como madrinas. Lamentablemente no hay ninguna información sobre la identidad de Joaquina o de Paula. Una posibilidad es que Paula fuera la pareja de un militar y elegirla fuera una manera de acceder a su esposo. También podría tratarse de mujeres con algún oficio respetable como el de partera, que les daba una cualidad muy estimable en aquellas sociedades rurales ${ }^{25}$.

Aunque se trata de una pequeña población, el análisis del compadrazgo en la villa de Belén permite mostrar la existencia de diversos vínculos entre familias, así como la forma en que la Guerra Grande afectó la vida cotidiana de los vecinos de la frontera. Si bien no se ha podido rastrear información que permita conocer en forma más profunda la identidad de estos vecinos y padrinos, la documentación relevada permitió constatar empíricamente las características del padrinazgo en una zona de frontera abierta y encontrar prácticas similares en esa región.

\section{El padrinazgo en el curato de Paysandú}

Las próximas páginas se centran en las características del compadrazgo en Paysandú en el período que se extiende desde la fundación de su parroquia hasta 1830. Se trata de una población más numerosa que la de Belén, el período de estudio es más extenso y se cuenta con otras fuentes que brindan información suplementaria a los registros bautismales.

Entre 1805 y 1830 se registraron 2.197 bautismos y su administración estuvo a cargo de más de una decena de sacerdotes. A diferencia del registro de Bernaola en Belén, los curas de Paysandú apenas anotaron los nombres del bautizado, sus padres y sus padrinos. En casi ningún caso se registró la condición étnica de padres y padrinos y en más del $60 \%$ tampoco se inscribió la del bautizado.

Más allá de las carencias del registro, interesa analizar qué características tuvo la población de Paysandú entre 1805 y 1830 . Al igual que en Belén, la anotación de personas como mestizos es casi inexistente, llegando a menos de un $1 \%$, resultado de

${ }^{24}$ Uruguay, ACES, Legajos de Bautismos $n^{0} 2$ de la Parroquia de Nuestra Señora de Belén, f. 25; legajo $\mathrm{n}^{\mathrm{o}} 3$, f. 11v, 13, 18.

${ }^{25}$ FARINATTI, Luís Augusto; MATHEUS, Marcelo Santos, ob. cit., p. 109. 
solo tres casos para todo el período ${ }^{26}$. En relación a la población indígena, alcanzó el $26 \%$, del cual en casi un $20 \%$ no se registró el grupo específico ${ }^{27}$. De todas maneras, de la lectura de los apellidos en ese grupo es probable que en número muy elevado fueran guaraníes.

Los curas de Paysandú no fueron exhaustivos en sus anotaciones, pero un aspecto que les interesó particularmente fue el de la legitimidad de los bautizados. Para los veinticinco años analizados, solo en dos casos no se registró esa condición. Las cifras de ilegitimidad son similares a las de otros sitios para el período ${ }^{28}$ e inferiores a las de la Parroquia de Belén²9.

A continuación se presentan algunas formas que adquirió el compadrazgo en el curato de Paysandú. Se trata de la elección de algunos casos concretos que permiten señalar aspectos singulares y comprobar características generales de esa práctica en el Río de la Plata.

\footnotetext{
${ }^{26}$ En los últimos años, la historiografía ha analizado en particular el tema del mestizaje. Los curas y los "funcionarios" aplicaron "reglas" para categorizar a una persona de una forma u otra. Judith Farberman y Roxana Boixadós han encontrado la aplicación de algunas de ellas. La categoría impuesta era el resultado de la intersección de la condición socioétnica con otros factores como la riqueza, la propiedad, la libertad jurídica, la dependencia de un cabeza de familia, la antigüedad de residencia en el poblado o la incorporación a una red más o menos importante en su comunidad. La consideración de todos estos aspectos "oscurecía" o "blanqueaba" a una persona. Es por ello que las cifras no reflejan tanto "entidades reales y objetivas, sino, y ante todo, construcciones intelectuales de los empadronadores". Al respecto Cf. BOIXADÓS, Roxana; FARBERMAN, Judith, "Clasificaciones mestizas. Una aproximación a la diversidad étnica y social en Los Llanos riojanos del siglo XVIII", Judith FARBERMAN y Silvia RATTO (coord.), Historias mestizas en el Tucumán colonial y las pampas (siglos XVII-XIX), Buenos Aires, Editorial Biblos, 2009, pp. 81- 88.

${ }_{27}$ La categoría utilizada incluye a los anotados como "indios", sin especificar el grupo particular. En forma separada hemos anotado a los guaraníes. En el primer grupo sumamos tres indios charrúas cristianizados que fueron bautizados en Paysandú en el período analizado.

${ }^{28}$ Para una comparación de las cifras de ilegitimidad en la frontera Cf. RIBEIRO, Max, Estratégias indígenas na frontera meridional: os guaranís missioneiros após a conquista lusitana (Rio Grande de Sāo Pedro 1801-1834), Porto Alegre, Dissertação (mestrado em História), UFRGS, 2013, p. 99.

${ }^{29}$ La parroquia de Paysandú tiene un 30\% de nacimientos ilegítimos entre 1805 y 1830, mientras que la Belén alcanza el 40\% entre 1838 y 1849. Al respecto Cf. AZPIROZ PERERA, Andrés Osvaldo, Relaciones de sociabilidad y poder en la frontera del litoral del río Uruguay al norte del río Negro, 1800-1852, Tesis para obtener el título de Magíster en Ciencias Humanas, opción Historia Rioplatense, FHCE, Udelar, Montevideo, febrero 2017.
} 


\section{Cuadro No 1 .}

Padrinos que concentran más ahijados en Paysandú, 1805-1830

\begin{tabular}{|l|l|l|l|l|}
\hline Padrino & $\begin{array}{l}\text { Atribución } \\
\text { socioétnica }\end{array}$ & Ocupación & $\begin{array}{l}\text { Cantidad } \\
\text { de ahijados }\end{array}$ & $\begin{array}{l}\text { Período de } \\
\text { tiempo }\end{array}$ \\
\hline José Aldao & blanco & comerciante & 19 & $1821-1830$ \\
\hline $\begin{array}{l}\text { Thomas } \\
\text { Paredes }\end{array}$ & blanco & $\begin{array}{l}\text { estanciero, } \\
\text { alcalde }\end{array}$ & 16 & $1807-1826$ \\
\hline $\begin{array}{l}\text { Crisanto } \\
\text { Suárez }\end{array}$ & guaraní & $\begin{array}{l}\text { músico de la } \\
\text { Iglesia }\end{array}$ & 15 & $1807-1826$ \\
\hline $\begin{array}{l}\text { Juan de la } \\
\text { Cruz Monzón }\end{array}$ & blanco & $\begin{array}{l}\text { alcalde (1820), } \\
\text { pulpero (1821), } \\
\text { capitán de } \\
\text { ć́vicos (1827) }\end{array}$ & 13 & $1807-1825$ \\
\hline Miguel Ojeda & blanco & $\begin{array}{l}\text { teniente de } \\
\text { milicias (1827) }\end{array}$ & 9 & $1822-1827$ \\
\hline $\begin{array}{l}\text { Bernardo } \\
\text { Posada }\end{array}$ & blanco & comerciante & 9 & $1820-1830$ \\
\hline Marcos Arce & sin dato & sin dato & 8 & $1821-1829$ \\
\hline $\begin{array}{l}\text { Nicolás } \\
\text { Benítez }\end{array}$ & indio & sin dato & 8 & $1816-1826$ \\
\hline Juan López & sin dato & sin dato & 8 & $1806-1826$ \\
\hline
\end{tabular}

Fuente: Elaboración propia con base en los libros 1 y 2 de la Parroquia San Benito de Paysandú.

José Aldao y Bonifacia Flores encabezan la lista de padrinos y madrinas de Paysandú para el período 1805-1830. José era "blanco", oriundo de Galicia, había nacido hacia $1777^{30}$ y según un registro de 1821 regenteaba una pulpería en Paysandú31. Bonifacia era "blanca", proveniente de San Salvador y había nacido diez años más tarde32. Ella era viuda de Bernabé Preste, con quien tuvo nueve hijos. Al fallecer su marido heredó una extensa estancia sobre el Queguay y un solar de una cuadra de frente por media de fondo en la villa de Paysandú33. Al contraer matrimonio con Aldao la pareja se estableció en el Queguay, aunque mantuvo los negocios en el pueblo34.

José reunió diecinueve ahijados, mientras que su esposa alcanzó los veintiuno. Como se puede apreciar de la conformación de las redes de cada uno, Aldao tuvo solo un ahijado en el que la madrina no fue su esposa. Bonifacia fue quien reunió más ahijados para el período analizado.

30 Uruguay, Archivo General de la Nación (en adelante AGN), Ex-Archivo General Administrativo (en adelante Ex-AGA), libro $n^{\circ}$ 277, Padrones de Paysandú, Padrón de habitantes de Paysandú, 1827.

${ }^{31}$ Uruguay, AGN, Ex-AGA, libro $n^{0}$ 277, Padrones de Paysandú, Relación de pulperías existentes en este departamento.

${ }^{2}$ Uruguay, AGN, Ex-AGA, libro $n^{0}$ 277, Padrones de Paysandú, Padrón de habitantes de Paysandú, 1827.

33 SCHULKIN, Augusto, Historia de Paysandú. Diccionario biográfico, Buenos Aires, Editorial Von Roosen, 1958, tomo I, p. 24.

34 Ibidem, p. 298. 
La pareja, que formaba parte de la elite local, estrechó sus relaciones con familias de su mismo entorno socioeconómico. A diferencia de otros padrinos de Paysandú, bautizaron a un solo ahijado de padre desconocido e ilegítimo35. Ambos apadrinaron a distintos hijos de comerciantes y estancieros, por ejemplo, a Gaspar Colman, hijo de Tadeo y María Clemencia Villanueva, vecinos de su estancia del Queguay36. Al mismo tiempo, Bonifacia fue la madrina de cinco hijos del comerciante castellano José Escudero, en tres de los casos con Aldao. Escudero residía en Paysandú donde era propietario de una pulpería37. José y Bonifacia fueron padrinos de José Felipe Iglesias Lavalleja, hijo de un próspero pulpero, propietario de una casa de ramos generales y sobrino de Juan Antonio Lavalleja ${ }^{38}$.

Como se mencionó en el caso anterior, el padrinazgo sirvió para establecer relaciones con familias que pertenecían a un mismo grupo social y desempeñaban actividades económicas similares. Además, en este caso la red se consolidó a partir del matrimonio de Aldao y Flores, más allá de que Bonifacia tenía un ahijado previo a su segundo matrimonio.

Tomás Paredes fue otro de los padrinos principales de Paysandú. Había nacido en San Salvador en 1772, proveniente de una familia de antiguo arraigo en la región. Su hermana estaba casada con José Patricio Gadea, integrante del Cabildo de Santo Domingo Soriano y eran los padres del religioso Lázaro Gadea. Paredes contrajo matrimonio con Cecilia Borges, oriunda de la Capilla del Espinillo, quien se encontraba viuda.

En 1804 fue uno de los vecinos que firmó el petitorio al obispo de Buenos Aires solicitando un curato con sede en Paysandú39. En 1810, cuando el levantamiento en el Río de la Plata, Paredes adhirió a la causa de la independencia. Junto con otros vecinos del pueblo como Jorge Pacheco, el cura Ignacio Maestre y José Arbide, se reunían en forma secreta en la casa del presbítero Silverio Antonio Martínez para debatir sobre las ideas políticas discutidas en esos años. En 1810, al bautizar a su hija

\footnotetext{
35 Uruguay, Parroquia San Benito de Paysandú, libro de bautismos no 2, f. 63v.

${ }^{6}$ SCHULKIN, Augusto, ob. cit., p. 298.

37 Uruguay, AGN, Ex-AGA, libro $n^{0}$ 277, Padrones de Paysandú, Relación de pulperías existentes en este departamento.

${ }^{38}$ SCHULKIN, Augusto, ob. cit., p. 211.

39 BARRIOS PINTOS, Aníbal, Paysandú. Historia General, Montevideo, Intendencia Municipal de Paysandú, tomo I, 1989, p. 102.
} 
María Narcisa Laureana, fueron sus compadres el "capitán de blandengues Jorge Pacheco" y su esposa, Dionisia Obes ${ }^{40}$. En 1813, cuando la villa dependía de Santo Domingo Soriano fue nombrado alcalde de Paysandú y en diciembre de ese año representó a su pueblo en el congreso de la Capilla de Maciel. En 1821 figura como propietario en el "Partido entre el Arroyo Negro don Estevan y Costa de Sánchez" de una estancia donde trabajaban cinco peones y un esclavizado41. En un censo de 1823 se registran cuatro mujeres de condición esclava, de cuatro a cuarenta años de edad ${ }^{42}$, y en el padrón de 1827 figura como residente en la villa, junto a su esposa, en una casa en la calle "2a" 43 . Años más tarde, en 1828 , fue alcalde interino 44 .

Tomás fue elegido en dieciséis ocasiones, seis de ellas acompañado de su esposa. Entre 1807 y 1810 fue padrino en cinco oportunidades y aparece registrado nuevamente en 1820, lo que confirmaría la ausencia en el poblado durante varios años. Como integrantes de la notabilidad local, Paredes y Borges se vincularon con varias familias de su mismo grupo social, aunque, a diferencia de los Aldao-Flores, establecieron vínculos de compadrazgo con familias amerindias. Por ejemplo, en 1808 fueron padrinos de una "india" de "padres desconocidos" y al año siguiente del hijo legítimo de un guaraní residente en el poblado45.

Paredes fue padrino de dos de los hijos de Juan de la Cruz Monzón, en uno de los casos junto a su esposa. Monzón era oriundo de Concepción del Uruguay y había integrado junto a su pareja el contingente de vecinos que había fundado Belén en 180146. En 1820 fue elegido juez real en los comicios donde también participó su compadre, Tomás Paredes47. En 1821 figura como propietario de una pulpería en el

\footnotetext{
40 Uruguay, Parroquia San Benito de Paysandú, libro de bautismos no 1, f. 53 v.

${ }^{41}$ Uruguay, AGN, Ex-AGA, libro no 277, Padrones de Paysandú, "Padrón que Manifiesta la fuerza de Indios y Haciendas según sus clases”, 1821.

42 SCHULKIN, Augusto, ob. cit., tomo III, p. 42.

43 Uruguay, AGN, Ex-AGA, libro $n^{0}$ 277, Padrones de Paysandú, Padrón de habitantes de Paysandú, 1827.

44 SCHULKIN, Augusto, ob. cit., tomo III, pp. 41-42.

45 Uruguay, Parroquia San Benito de Paysandú, libro de bautismos no 1, f. 25 y f. 36.

46 DÁVILA, Adriana; AZPIROZ, Andrés, Indios, cautivos y renegados en la frontera. Los blandengues y la fundación de Belén, 180o-1801, Montevideo, Ediciones Cruz del Sur, 2015, p. 96.

47 SCHULKIN, Augusto, ob. cit., tomo II, p. 405.
} 
pueblo de Paysandú48, con cuatro trabajadores a cargo, dos de los cuales eran esclavizados49, y en 1827 como "capitán de cívicos”5o.

Juan de la Cruz Monzón reunió trece ahijados, de los cuales la mayoría los compartió con su segunda esposa, Juliana Nieto. La jerarquía de los padrinos era un aspecto relevante, pues por lo general los padres elegían a personas de su misma condición social o superior. Así, en 1820, cuando Monzón era alcalde de Paysandú, fue elegido padrino en cinco oportunidades ${ }^{5}$. Fue padrino de un hijo ilegítimo y de “padre desconocido" de María Micaela Moreira, pero también del hijo de Cipriano Brian, uno de los carniceros del pueblo52 y de Fausto Alemán, un estanciero, quien en un padrón de 1821 figura con nueve peones en su establecimiento53.

En muchos de los casos señalados hasta ahora la relación padrino-padre puede ser caracterizada como clientelar54. Ese podría ser el caso de Juan de la Cruz con los ahijados que se mencionaron o los bautismos analizados para Tomás Paredes y su esposa Cecilia Borges. Por el contrario, hubo padrinos como José Aldao y Bonifacia Flores que, al menos a partir de las fuentes disponibles, mantuvieron relaciones de compadrazgo con otros de su misma condición: vecinos, propietarios y funcionarios. El prestigio social, el poder económico o el ejercicio del poder, cualquiera fuere su manifestación, eran las condiciones que debía reunir un padrino o una madrina para ser preferido por tantos padres. José, Bonifacia, Tomás, Cecilia, Juan de la Cruz y Juliana fueron parte del grupo de padrinos preferidos en Paysandú. Todos eran "vecinos" y propietarios, tanto en el pueblo como en las afueras, y seguramente todos tenían trabajadores esclavizados. Compartían las mismas actividades económicas y el compadrazgo fue una ocasión para estrechar esas redes con sus vecinos y eventuales socios. Al prestigio derivado de su poder económico, Tomás Paredes y Juan de la

${ }^{48}$ Uruguay, AGN, Ex-AGA, libro $n^{0}$ 277, Padrones de Paysandú, Relación de pulperías existentes en este departamento.

49 Uruguay, AGN, Ex-AGA, libro no 277, Padrones de Paysandú, "Padrón que Manifiesta la fuerza de Indios y Haciendas según sus clases”, 1821.

${ }^{50}$ Uruguay, AGN, Ex-AGA, libro $\mathrm{n}^{\circ}$ 277, Padrones de Paysandú, Padrón de habitantes de Paysandú, 1827.

${ }^{11}$ Uruguay, Parroquia San Benito de Paysandú, libro de bautismos no 1, f. 84, 86, 91, 92, 94.

52 Uruguay, AGN, Ex-AGA, libro ${ }^{\circ}$ 277, Padrones de Paysandú, Padrón de habitantes de Paysandú, 1827.

53 AGN, Ex-AGA, libro n ${ }^{0}$ 277, Padrones de Paysandú, "Padrón que Manifiesta la fuerza de Indios y Haciendas según sus clases", 1821.

54 SANTILLI, Daniel, "Representación gráfica de redes sociales. Un método de obtención y un ejemplo histórico", Mundo Agrario, vol. III, nº 6, enero-junio 2003, p. 15. 
Cruz Monzón sumaban el poder político, pues ambos formaron parte del núcleo de autoridades políticas de Paysandú entre 1805 y 1830.

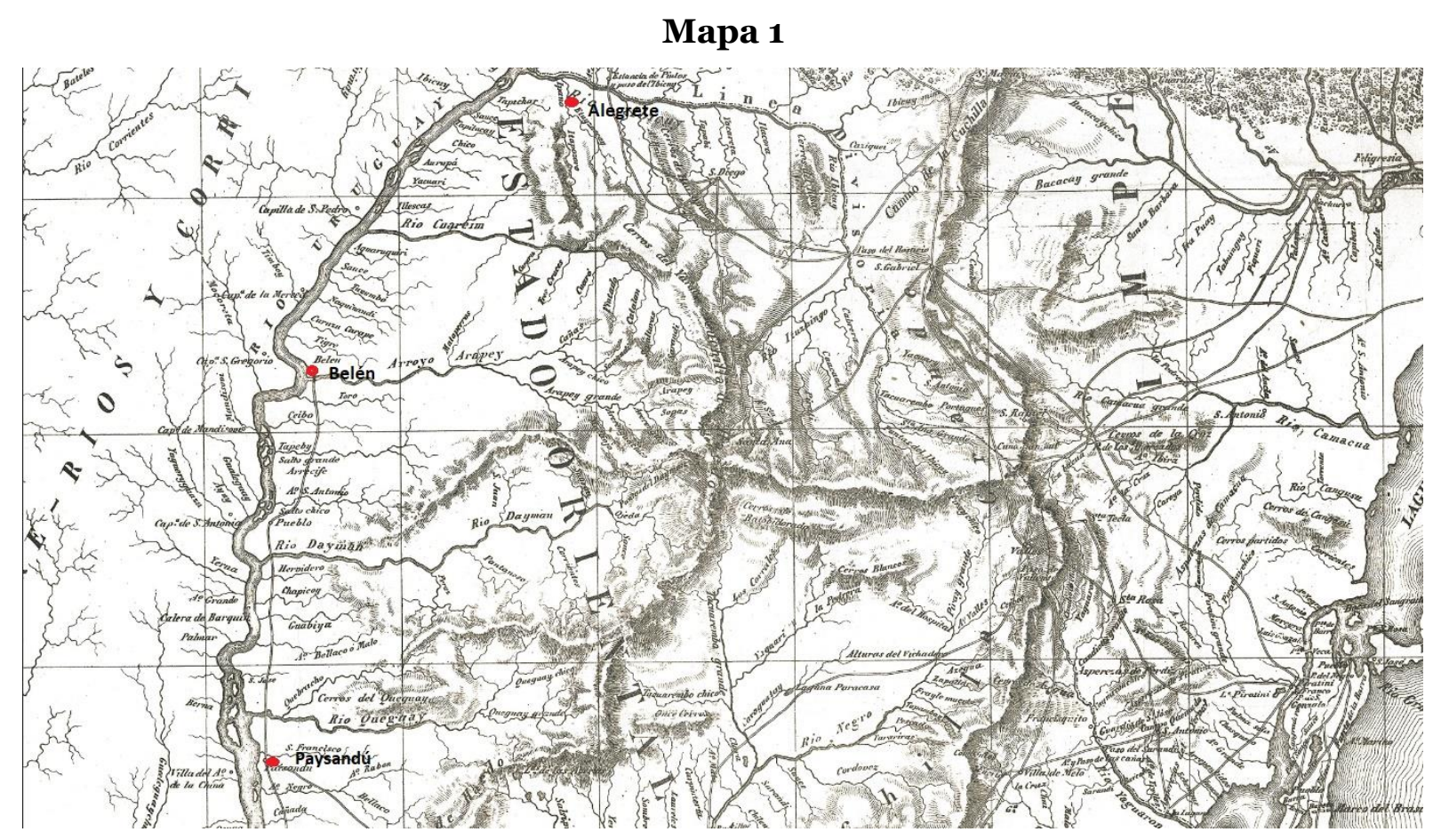

El mapa indica las sedes de las parroquias de Paysandú, Belén y Alegrete. El espacio recortado da cuenta del espacio aludido en el trabajo.

Fuente: Carta Geográfica del Estado Oriental del Uruguay y posesiones adyacentes según los documentos más recientes y exactos publicado bajo la dirección del Sr. Aimé Roger, Cónsul de Francia, 1841. Colección Museo Histórico Nacional, Uruguay.

\section{Capilla de Alegrete}

La capilla de Alegrete fue erigida por los portugueses en los primeros años de la década de 1810 en las proximidades del río Inhanduí, pero al poco tiempo fue atacada y quemada por las fuerzas de Andresito Artigas. Luego, fue reconstruida y definitivamente instalada en 1817 en un lugar próximo a las orillas del río Ibirapuitã, donde se localiza hoy la región sudoeste del estado brasileño de Río Grande del Sur. Su jurisdicción fue imprecisa y variable a lo largo de la primera mitad del siglo XIX, pero se estima que abarcó las regiones entre los ríos Ibicuí, al norte, y Quaraí, al sur. Asimismo, es posible que durante algunos períodos, como parte de la década de 1820, también se hubiera incorporado la región entre los ríos Quaraí y Arapey.

La instalación de esa capilla significó un acto político por parte del expansionismo lusitano en el sur de América. Se trataba de establecer un elemento institucional del Imperio Portugués en las tierras que eran disputadas con otros 
actores geopolíticos en aquel momento. De hecho, durante toda la primera mitad del siglo XIX fue una región en la que diferentes proyectos de soberanía disputaron el espacio, incluso superponiéndose: los imperios coloniales ibéricos, después el Imperio de Brasil, las fuerzas de Artigas, algunas de las entidades políticas que emergieron en el territorio del antiguo Virreinato del Plata, la efímera República Riograndense (1836-1845).

Ese espacio formaba, desde fines del siglo XVIII, una típica zona de frontera. Esos campos integraban las estancias de los pueblos misioneros, en los cuales, como han mencionado diversos autores, se desarrolló un sistema productivo específico con una economía ganadera propia.

Los registros de bautismo de la capilla de Alegrete a los que pudimos tener acceso comienzan a ser regulares a partir de 1821 . No obstante, aparecen registradas 5.227 partidas de bautismo realizadas entre 1816 y 1845 . El período va desde la instalación de la capilla hasta el término de la Revolución Farroupilha. En ese tiempo, un $80 \%$ de los bautizados eran libres, $19 \%$ esclavos y 1\% libertos. Hasta 1835 , $89 \%$ de los registros de bautizados libres contenían, junto con sus nombres, alguno de estos calificativos: blanco(a), indio(a), china, de nación guaraní, pardo(a), mulato(a), mestizo, "preto"55(a), negro(a). La presencia de esos calificativos decayó mucho después de esa fecha, especialmente a partir de 1840. En el caso de madres, padres, madrinas y padrinos esas designaciones fueron adjudicadas en algunas pocas ocasiones. Para ellos, aparecen calificativos como doña y capitán.

Llama la atención la presencia de bautizados apuntados como indio(a), china o “de nación guaraní". Ellos eran, entre 1816 y 1828, el 52\% de los bautizados, y el 32\% entre 1828 y 1835 . Cerca de cuatro quintos de las madres de aquellos bautizados era natural de los pueblos de las Misiones; en cambio, el quinto restante se dividía entre Río Grande de San Pedro y áreas de habla "española". En lo que se refiere a los nombrados expresamente como "blancos", la proporción se invertía y la inmensa mayoría provenía de las áreas de colonización portuguesa, especialmente de las regiones limítrofes con aquella frontera, en Río Grande de San Pedro. Esos datos, sumados a la escasa presencia de bautizados nombrados con categorías que

55 "Preto", refiere a una expresión en portugués usada por los sacerdotes. En el siglo XIX, era el término más corriente para designar a las personas de piel oscura, prefiriéndose al uso del adjetivo "negro". 
remitieran expresamente al mestizaje (pardo, mulato, mestizo), indican que el proceso de conquista reciente de la región era una clave clasificatoria sustantiva para los religiosos que hacían los registros. En ese sentido, "blanco" parece haber sido asociado frecuentemente a los conquistadores luso-brasileños y no estrictamente al color de piel de los padres o del bautizado.

Véase entonces que los registros de Alegrete expresan muy bien la realidad de una capilla de frontera donde había expansionismo luso-brasileño y, con ello, la incorporación de los africanos y afro-brasileños esclavizados, junto con un gran contingente de población guaraní misionera y un pequeño número de naturales de regiones de habla española como la Banda Oriental, Corrientes y Entre Ríos.

El conjunto documental analizado permitió la realización de una serie de estudios sobre temas específicos más conectados entre sí: familia y legitimidad; migraciones y reordenación espacial; compadrazgo esclavo ${ }^{56}$. Entre esos trabajos, hay un análisis particular de aquellos padrinos y madrinas que bautizaron muchos ahijados en la capilla de Alegrete durante el período estudiado57. Aquí, retomamos parcialmente esas conclusiones para realizar una comparación con Belén y Paysandú, parroquias que se pueden considerar como pertenecientes a la misma zona de frontera, pero bajo jurisdicción del Estado Oriental.

\section{Padrinos y madrinas principales en la capilla de Alegrete (1821-1845)}

Para este estudio seleccionamos todas las parejas en las cuales por lo menos uno de los conyugues apadrinó quince o más veces. Además del compadrazgo de cada uno de esos padrinos/madrinas principales, incluimos en el análisis los bautismos en los que su cónyuge se presentó a la pila bautismal con otro compañero. Así, llegamos

\footnotetext{
${ }^{56}$ FARINATTI, Luís Augusto, “A espada e a capela”, História Unisinos, vol. 16, $\mathrm{n}^{\circ}$ 3, 2012, pp. 294306; FARINATTI, Luís Augusto, "Gente de todo lado: deslocamentos populacionais, registros de batismo e reordenação social na fronteira meridional (Alegrete 1816-1845)", Ana Silvia V. SCOTT; , José Carlos S. CARDOZO y otros (orgs.), História da Família no Brasil Meridional. Temas e perspectivas, São Leopoldo: Oikos Editora, 2014, pp. 215-238; FARINATTI, Luís Augusto; RIBEIRO, Max Roberto P, "Guaranis nas capelas da fronteira: migrações e presença missioneira no Rio Grande de São Pedro (Alegrete e Santa Maria, 1812-1827)”, XII Simpósio Internacional HIU. A experiência missioneira: território, cultura e identidade, CD-ROM, 2010 y FARINATTI, Luís Augusto; VARGAS, Jonas M., "Elites regionais, guerra e compadrio: a família Ribeiro de Almeida e suas redes de relações (Rio Grande do Sul, 1816-1844)”, Topoi (Online): revista de História, vol. 15, 2014, pp. 389-413.

57 FARINATTI, Luís Augusto, "Padrinhos preferenciais e hierarquia social na fronteira sul do Brasil (1816-1845).”, en Roberto GUEDES; João L. R. FRAGOSO (orgs.), História social em registros paroquiais (sul-sudeste do Brasil, séculos XVIII e XIX), Rio de Janeiro: Mauad X, 2016, pp. 102-128.
} 
a dieciséis parejas que se encontraban en esa condición. De ellas, quince pertenecían a la elite local. Tenemos referencias de ellos en escrituras públicas, inventarios post mortem, menciones de deudas y correspondencias administrativas. En seis casos se trataba de grandes estancieros y además, los hombres eran oficiales de milicia o de la Guardia Nacional, según del período. Otros cuatro eran grandes estancieros o comerciantes que ocuparon cargos en la administración civil del distrito, más tarde municipio de Alegrete. Las últimas cinco parejas eran de grandes estancieros, que podían ser también negociantes de tropas de ganado y actuar como prestamistas, pero que no tenían permisos y no ocuparon cargos públicos, por lo que los hemos referido como "elite económica". Finalmente, estaban Vicente Aleixo y Bernardina Flora, la única pareja de padrinos estudiados que no pertenecían a la elite; son nombrados como "indios" en los registros y no aparecen en ninguna fuente patrimonial investigada.

Así como vimos en los casos de Belén y Paysandú, la posesión de grandes propiedades en un selecto grupo de la elite económica local define la mayoría de esas parejas de padrinos/madrinas. La acumulación de importantes recursos económicos era un factor de prestigio y un atractivo para que madres y parejas de igual o inferior posición social vieran en ellos posibilidades como compadres y comadres. Sin embargo, eso no explica todo. Muchas otras parejas de la elite no recibían la misma búsqueda. Además, dentro de ese grupo, en los casos donde los maridos eran oficiales milicianos, las parejas ganaban destaque. Ellos eran invitados por varios grupos sociales, incluso por otros miembros de la elite. En contrapartida, aquellos que eran "apenas" estancieros raramente eran invitados a bautizar hijos de oficiales milicianos, indicando la jerarquía de estos últimos.

En el siglo XVII para el caso de Río de Janeiro y en el XVIII para el de Río Grande de San Pedro, el derecho de conquista y el ejercicio del mando a partir de éste se reiteraron en las costumbres de las elites luso-brasileñas que actuaban en la expansión de áreas de frontera. Imperaba un ethos de servicio a la monarquía a partir de los propios recursos, en cambio de tierras, del reconocimiento regio y del reparto del poder local 58 . Algunos de esos principios continuaron operando hasta fines del

$5^{8}$ FRAGOSO, João, ob. cit., 2003; KUHN, Fabio, ob. cit.; HAMEISTER, Martha; GIL, Thiago. "Fazerse elite no extremo-sul do Estado do Brasil: uma obra em três movimentos: continente do Rio Grande de São Pedro (século XVIII)”, João Luis Ribeiro FRAGOSO; Antonio Carlos Jucá SAMPAIO y Carla 
siglo XVIII en áreas de frontera como Río Grande, aunque la administración portuguesa pasara a tener aspiraciones centralistas y universalizantes desde los tiempos pombalinos59. De hecho, la situación de frontera y guerras recurrentes del extremo sur parece haber potenciado esa situación. El manejo de los reclutamientos, la posibilidad de distribución de botines, la conquista y avance territorial al servicio de la Corona tornaban aún más concretos los significados de portar un puesto de milicias junto al nombre y ser así reconocido en la comunidad.

$\mathrm{Al}$ inicio del siglo XIX, la época de las independencias en América Ibérica, se potenciaron las apropiaciones creativas de todo un léxico político-jurídico de matriz individualista. No obstante, en ese mismo contexto, la expansión de los lusobrasileños hacia el sur estimuló la necesidad de que la Corona portuguesa se valiera del servicio de los liderazgos milicianos regionales y fomentara una pródiga distribución de tierras en forma de sesmaría entre los años de 1811 y $1822^{60}$. Las primeras cuatro décadas del siglo XIX propiciaron la emergencia de liderazgos armados que operaban tanto con formulaciones específicas de conceptos de libertad, ciudadanía y constitución, como con actualizaciones de las categorías de servicio, merced y ejercicio del poder local. Era esa elite la que se destacaba en los tiempos de la conquista y reordenamiento de dicha frontera. Las posibilidades abiertas por la conquista militar de la región eran compatibles con actualizaciones de algunas de las prácticas tradicionales, que componían las referencias culturales de aquellas familias.

Conocidos los trazos generales de los conjuntos de compadres de los padrinos/madrinas principales de Alegrete, un estudio micro analítico comparando los conjuntos de compadres permite explorar la diversidad de los recursos relacionales existentes y su distribución desigual en la jurisdicción de la parroquia.

Como ya mencionamos, las parejas de padrinos/madrinas recibían invitaciones de personas de variada condición social. No obstante, nuevos elementos

Maria Carvalho ALMEIDA (orgs.), Conquistadores e negociantes: história de elites no Antigo Regime nos Trópicos. América Lusa, séculos XVI a XVIII, Rio de Janeiro, Civilização Brasileira, 2007, pp. 265-310.

59 XAVIER, Angela Barreto; HESPANHA, António Manuel, “A representação da sociedade e do poder”, José MATTOSO, (org.), História de Portugal - vol. 4. O Antigo Regime, Lisboa, Editorial Estampa, 1998, pp. 120-155.

6o OSÓRIO, Helen, Apropriação da Terra no Rio Grande de São Pedro e a formação do espaço platino. Dissertação (mestrado em História), UFRGS, Porto Alegre, 1990. 
emergen cuando analizamos la distribución desigual de esos compadres en los conjuntos de las diferentes parejas. Colocados en perspectiva, ellas forman un continuum. Un análisis comparativo de los compadres de dos parejas donde el marido era oficial miliciano logra reconstruir de modo más complejo las relaciones establecidas y los diferentes recursos en juego en aquella frontera. La propuesta es analizar las características del compadrazgo en dos casos concretos: a) Teniente Coronel João Machado de Bittencourt y sus esposas. La primera, Doña Felícia Gomes de Oliveira y, luego de quedar viudo, el matrimonio con su sobrina Doña Rita Gomes de Oliveira; b) Coronel Bento Manuel Ribeiro y Doña Maria Mâncio da Conceição. Además de las personas que los invitaron para bautizar sus hijos, incluimos en el estudio los padrinos/madrinas de sus propios hijos, fragmentos del espacio relacional de sus familiares más próximos y parte de sus trayectorias de vida, con atención a los cambios a lo largo del tiempo.

Consiste en parejas de padrinos, todos del mismo medio social, grandes estancieros e importantes oficiales milicianos, además de que eran compadres entre sí: Bittencourt era padrino de un hijo de Bento Manuel y Maria Mâncio. Sin embargo, como se puede ver en el cuadro $\mathrm{N}^{\circ}$ 2, las formas de sus conjuntos de compadrazgo son bastante distintas.

\section{Cuadro No 2}

\section{Comparación conjuntos de compadrazgo de parejas de oficiales de milicia} (Alegrete, 1816-1845)

\begin{tabular}{|l|c|c|c|c|c|c|}
\hline & $\begin{array}{l}\text { Oficiales } \\
\text { Milicia }\end{array}$ & Subalternos & $\begin{array}{l}\text { Elite } \\
\text { económica }\end{array}$ & Familia & Otros & Total \\
\hline $\begin{array}{l}\text { João Machado de } \\
\text { Bitencourt, Felícia Gomes } \\
\text { de Oliveira y Rita Gomes } \\
\text { de Oliveira }\end{array}$ & 1 & 15 & 0 & 5 & 9 & 30 \\
\hline $\begin{array}{l}\text { Bento Manuel Ribeiro y } \\
\text { Maria Mâncio da } \\
\text { Conceição }\end{array}$ & 11 & 6 & 3 & 3 & 5 & 28 \\
\hline
\end{tabular}

Fuente: Archivo de la Diócesis de Uruguaiana (ADU), RS, 1816-1845, Libro de Bautismos Capilla de Alegrete, n.1, n.2, n.3 y Libro de Esclavos.

En el caso del Teniente Coronel João Machado de Bittencourt y sus esposas tenemos gran cantidad de subalternos y un número razonable de personas de la

${ }^{61}$ Como "subalternos" agregamos: madres solteras de cualquier color o condición; padres y madres de bautizados libres cuyo color fue indicado por el párroco como indio, china, mestizo, pardo o "preto"; padres y madres esclavos o libertos. 
propia familia que los invitaron a bautizar a sus hijos. En contrapartida, allí hay solo un oficial miliciano y se trataba justamente del Coronel Bento Manuel Ribeiro, justo al inicio del período estudiado. Por su parte, el Coronel Bento Manuel y su esposa doña Maria Mâncio tenían un conjunto de compadres bastante distinto, donde es notable la presencia de oficiales milicianos, con pocos familiares y subalternos. Vamos a hacer un análisis de cada uno de esos casos.

El Teniente Coronel João Machado de Bittencourt era natural de Río Pardo, la principal base de donde partió el avance de los luso-brasileños sobre los territorios disputados con España. Tenía cerca de 70 años en la década de 1820 y era un veterano de las guerras de frontera. Se casó por primera vez con doña Felícia Gomes y, cuando ésta falleció, contrajo matrimonio con su sobrina, doña Rita Gomes ${ }^{62}$. La familia de sus esposas era tradicional en Río Grande de San Pedro, emparentada con Rafael Pinto Bandeira, uno de los mayores líderes de la frontera meridional en la segunda mitad del siglo XVIII. Sus comadres/compadres subalternos incluían seis padres de "indios" (cuatro parejas y dos madres solteras), cinco madres solteras esclavas (un niño fue manumitido en la pila bautismal), dos madres solteras de niños blancos, una pareja de esclavos, una pareja de pardos libres y un esclavo africano. Los padres y madres de "indios" eran todos originarios de los antiguos treinta pueblos de las Misiones. Entre ellos, los más representados eran el pueblo de San Luis y el de San Miguel, con una pareja y una madre soltera cada una.

Hasta 1829, año del fallecimiento de doña Felícia, la pareja mantuvo en su estancia un oratorio privado donde se realizaban ceremonias de bautismo, sin que se precisara ir hasta la Capilla de Alegrete. Allí se hicieron 59 bautismos, con 43 niños libres, 1 liberto, 11 esclavos, más 4 esclavos africanos. De los niños libres, 22 fueron registrados como indios. Entre las madres de ellos, ocho eran nacidas en el pueblo de San Luis; los otros orígenes tenían solo una o dos representantes. Esa presencia mayoritaria del pueblo de San Luis también se verificaba, como vimos, entre las comadres y compadres indios de Bittencourt, Felícia Gomes y Rita Gomes, aunque de manera menos pronunciada ${ }^{6}$.

62 Antigualhas, histórias e genealogia, In: http://pufal.blogspot.com.br/2012/01/familiasportuguesas-nas-missoes.html, acceso el 23-07-2014.

63 Brasil, Arquivo da Diocese de Uruguaiana (en adelante ADU), Livro de Batismos Capela de Alegrete, n.1, n.2, n.3. 
Agreguemos la información de que el nombre de la estancia perteneciente a Bittencourt, donde se localizaba el oratorio privado, era justamente la estancia San Luis. La historia es aún más interesante cuando sabemos que entre 1808 y 1810, cerca de una década antes del período tratado, Bittencourt fue el administrador nombrado por la corona portuguesa para el recién conquistado pueblo misionero de San Luis, al norte del Río Ibicuí. En 1810, cuando fue sustituido, fue acusado de haberse apropiado de tierras, ganado y armamento pertenecientes a aquel pueblo ${ }^{64}$. Sin embargo, seis años después, estaba en el comando de una compañía miliciana de apoyo al ejército portugués, en una nueva campaña contra el jefe oriental José Artigas.

Entre sus compadres, la gran cantidad de indios, la presencia de esclavos, personas de la familia de doña Rita y también sujetos registrados sin distinción de notabilidad indican que el oratorio de la estancia San Luis era un lugar que atraía vecinos, parientes, agregados y los eventuales esclavos de esas familias. Además, expresa una posible alianza con grupos parentales egresados del pueblo de San Luis, tal vez remontando al tiempo en el cual Bittencourt había sido administrador del pueblo.

En sus estudios sobre las diferentes regiones de Río Grande de San Pedro en el siglo XVIII, Martha Hameister y Bruna Sírtori destacaron la importancia de no limitarse al estudio del compadrazgo de una persona o pareja, en aquel universo donde regía una concepción de familia más amplia ${ }^{65}$. Para las autoras, un análisis más completo debería incluir, por lo menos, los familiares más próximos de la pareja estudiada y sus esclavos. En ese sentido, es interesante notar cómo familiares de Rita y Felícia Gomes de Oliveira también tenían un patrón de compadrazgo semejante. Su hermano Davi Gomes de Carvalho también era uno de los padrinos principales y su hermana Ana Gomes de Oliveira tenía catorce ahijados. En ambos casos, se destaca la presencia de subalternos entre sus compadres. Ellos bautizaron tanto en la Capilla de Alegrete como en el oratorio de la estancia San Luis, a veces fueron acompañados por Bittencourt o Rita Gomes. Probablemente eran vecinos de las tierras de la estancia. La esposa de Davi y el marido de Ana Gomes bautizaron solo una vez y siempre

64 Brasil, Arquivo Histórico do Rio Grande do Sul (en adelante AHRS), Fundo Autoridades Militares, 23.07.1810, Francisco das Chagas Santos. Agradecemos ao historiador Max Roberto Ribeiro a cessão de uma cópia fotográfica desse documento.

65 HAMEISTER, Martha D., ob. cit.; SIRTORI, Bruna, ob. cit. 
acompañaron sus cónyuges. Entre sus quince ahijados, Davi Gomes tenía solamente subalternos (cinco indios, cinco esclavos y cuatro pardos libres y libertos) y el hijo de una pareja sin notabilidad. Ana Gomes bautizó catorce niños, de los cuales cinco eran indios, tres esclavos y seis hijos de personas de su familia.

Bento Manuel Ribeiro fue un importante jefe político y militar en Río Grande del Sur durante la primera década del siglo XIX. Ascendió en las campañas de la frontera en la década de 1810 y fue promovido a coronel y comandante de la frontera de Alegrete al inicio de la década siguiente. En la Revolución Farroupilha, tuvo un papel destacado y controvertido, por cambiar de lado tres veces a lo largo del conflicto. Al final, había sido General de la República Riograndense y Mariscal del Imperio Brasileiro ${ }^{66}$.

El conjunto de compadres del coronel Bento Manuel y de Doña Maria Mâncio, a su vez, se mostraba diferente del analizado anteriormente ${ }^{67}$. Allí, también había gran heterogeneidad social, pero es llamativa la presencia de oficiales de milicia. Todos ellos eran también importantes estancieros en la parroquia de Alegrete. Es relevante conocer que 7 de las 11 ocasiones donde se bautizaron hijos de esos oficiales fueron entre 1822 y 1824, cuando Bento Manuel ocupaba el cargo de Comandante de la Frontera. Los padres de los niños eran oficiales de grado más bajo que Bento Manuel. En cinco casos, se trataba de los primeros hijos de esos oficiales. En los otros dos, el primer hijo fue dado para alguien de la familia de los padres para bautizar y el segundo permitió establecer relaciones con el comandante. El compadrazgo entre ellos mismos surgiría en los siguientes años, cuando sus próximos hijos fuesen dados para bautizar a otros miembros del grupo, formando un conjunto fuerte de compadrazgo y, como se puede verificar por otros documentos, de efectiva alianza militar y política ${ }^{68}$. Las alianzas dentro del cuerpo militar, miliciano y político fueron

\footnotetext{
66 FARINATTI, Luís Augusto, Confins Meridionais: famílias de elite e sociedade agrária no sul do Brasil (1825-1865), Santa Maria, Editora da UFSM, 2010.

${ }_{67}$ Las conclusiones referentes específicamente al compadrazgo de la pareja Bento Manuel y Maria Mâncio fueron desarrolladas con más detenimiento en otros dos artículos. Ver nota $n^{0} 56$.

68 FARINATTI, Luís Augusto; VARGAS, Jonas, ob. cit.
} 
comunes en varias regiones de la provincia en el contexto de la expansión de la frontera, al inicio del siglo XIX ${ }^{69}$.

Por otro lado, Bento Manuel apadrinó apenas un niño indio, hijo del capitán Athanásio Ababos, "indio guaraní del pueblo de San Tomé" y de su esposa doña Candelária Candi, "india del pueblo de San Luis". Es la única vez en la cual los vocablos "india" y "doña" aparecen juntos en un registro. Solo en dos casos hay padres de indios que presentan grado de oficiales de milicia. El compadrazgo, realizado en 1831, parece haber ritualizado una efectiva alianza de apoyo. En sus memorias, el magistrado Francisco de Sá Brito relató que, cuando el coronel Bento Manuel cambió por primera vez de lado en la Revolución Farroupilha, escribió a otros jefes militares para pedir que lo acompañaran; uno de los que atendió al llamado fue "el Capitán Athanásio y su cuerpo de lanceros" 70.

En este caso, aparece la construcción de una elite ligada a la guerra y a un mismo cuerpo de oficiales milicianos. La posición prominente de Bento Manuel dentro de ese grupo se manifiesta en su condición de compadre preferido, vinculado a su grado superior. Es probable que este conjunto de aliados haya sido uno de los recursos del cual él pudo valerse para cambiar de lado tres veces durante la Revolución Farroupilha (1835-1845), ocupando puestos de liderazgo en ambos lados.

Otra diferencia con el caso de Bittencourt es que Bento Manuel no tenía un oratorio en su estancia. Además de tierras poseía una casa en la villa de Alegrete, donde quedaba la Capilla. Sus compadres, cuyas relaciones habían sido generadas en las campañas militares anteriores, tenían sus propiedades en diferentes extremos de la capilla, distando, en algunos casos, más de cien kilómetros unas de las otras. La población de Alegrete parece haber funcionado, en ese caso, como un lugar aglutinador, propiciando encuentros y ayudando a la visibilidad social de los Ribeiro de Almeida.

69 COMISSOLI, Adriano, "Continuo a ter espias para saber o que mais respirar": comandos de fronteira e redes de informação na fronteira platina do império português (séc. XIX)”, Revista Ultramares, vol. 5, 2016, pp. 127-159.

70 FARINATTI, Luís Augusto, ob. cit., 2012. 
En estudios anteriores se ha analizado el compadrazgo de esta pareja junto con el de sus hijos ${ }^{71}$. La pareja de su hija Ana Dorotea y el de su hijo Severino Ribeiro también pertenecían al restringido círculo de las dieciséis parejas principales estudiadas aquí. Ana Dorotea apareció por primera vez como madrina a los 12 años, acompañada de su padre. En el siglo XVIII, la presencia de niñas-madrinas era una práctica también en la villa de Río Grande y probablemente formaba parte de las estrategias familiares de constitución de un capital de relaciones sociales que se reiterara en el tiempo ${ }^{72}$. Fue ella quien a los 21 años ya era madrina de nueve niños y acompañó el estreno de su joven hermano Severino como padrino, unión que se repitió siete veces más dentro del período estudiado. Esa configuración sugiere que la invitación para apadrinar en este caso era mucho más familiar que individual e indica una estrategia de construcción de alianzas sociales. Ana Dorotea fue la persona que más ahijados bautizó en la capilla de Alegrete dentro del recorte temporal analizado en este artículo, con 35 ahijados. Así, la familia Ribeiro de Almeida manejaba la reiteración de su patrimonio inmaterial, garantizando un ampliado capital de relaciones de reciprocidad y jerarquía con diferentes sectores sociales, pero con importante acento en el cuerpo de oficiales de milicia del cual Bento Manuel era una referencia.

Ahora, veamos una nota sobre a quiénes esos dos oficiales elegían para apadrinar sus hijos. Bittencourt y Felícia no tuvieron descendencia. Del segundo casamiento del teniente coronel con Rita Gomes nació solo una hija, cuyos padrinos fueron los tíos de Rita, linderos de la estancia San Luis, elegidos entre sus vecinos y familiares73. Nuevamente, hay una configuración más cerrada en torno de una comunidad de parientes, vecinos, agregados y esclavos. A su vez, cuatro hijos de Bento Manuel y Maria Mâncio fueron bautizados en Alegrete. Uno de ellos no tuvo padrinos, otro fue apadrinado por los abuelos maternos, otro por el teniente coronel Bittencourt, al inicio del período estudiado cuando era oficial superior a Bento Manuel, y el último por un renombrado oficial miliciano ajeno a Alegrete, con actuación en toda la provincia. Hemos constatado que la pareja no retribuyó ninguna

\footnotetext{
${ }^{71}$ FARINATTI, Luís Augusto. "Famílias, relações de reciprocidade e hierarquia social na fronteira meridional do Brasil (1816-1845), ENCONTRO ESTADUAL DE HISTÓRIA, 10, Anais eletrônicos (http://www.eeh2010.anpuh-rs.org.br/site/anaiscomplementares\#L). Santa Maria: ANPUH-RS UFSM $2010 \mathrm{~b}$.

72 HAMEISTER, Martha, ob. cit., 2006.

73 Brasil, ADU, RS, 09.07.1834, Livro de Batismos Capela de Alegrete, n.2, f. 196v.
} 
de las invitaciones hechas por los oficiales de Alegrete, prefiriendo un gran liderazgo regional o sus propios familiares, habitantes de las áreas antiguas de colonización. Esto es coherente tanto con el carácter provincial de la actuación de Bento Manuel, como también con el papel de mediador que desempeñaba entre la comunidad de Alegrete y sus alrededores. Además, como ya demostramos, esa es una relación revelada en diversos documentos 74 .

Las diferencias entre las características de los conjuntos de compadres de esas dos parejas que participaban de un mismo grupo social demuestran la variedad de recursos en juego y la "topografía" de aquel espacio social. Alianzas con parientes, con otros grupos de la elite, con poblaciones "indígenas" residentes de las áreas fronterizas o recién-conquistadas. Estos factores son mencionados en los estudios sobre los compadrazgos de las familias de la elite de diferentes regiones del Río Grande de San Pedro hasta el siglo XIX75. Los autores argumentan que esas alianzas permitían construir una base de legitimidad y apoyo ligada en diversas orientaciones del espacio social, fortaleciendo la posición de esas elites. Podemos decir que el establecimiento de ese conjunto de vínculos, así como de grupos de relaciones jerarquizadas, fueron rasgos reiterados de la expansión luso-colonial en el sur de América. Ellas replicaban, en cierta medida, patrones existentes en otras épocas y lugares, como el Río de Janeiro del siglo XVII. Como ya dijimos, esas regiones tenían en común la situación de frontera colonial en expansión o de territorio de conquista reciente.

Ese argumento es consistente con el análisis de los casos aquí expuestos, que indica la reiteración de esas prácticas en la frontera recién conquistada a lo largo de la primera mitad del siglo XIX. Además, el ejercicio comparativo entre los conjuntos de compadres permite mostrar las diferentes estrategias y la distribución desigual de esos recursos entre las familias de la elite. El poder del comandante miliciano estaba construido, en un caso, por una alianza con parcialidades de guaraníes misioneros, además de un fuerte enraizamiento vecinal y familiar. En otro caso, las campañas contra los hispanocriollos, primero victoriosas y después derrotadas, marcaban las alianzas entre un grupo de jóvenes oficiales en torno de un líder. Este agregaba, pero

\footnotetext{
74 FARINATTI, Luís Augusto, "A espada e a capela”, ob. cit.

75 KHUN, Fabio. ob. cit.; HAMEISTER, Martha, ob. cit.; HAMEISTER, Martha; GIL, Thiago, ob. cit.; SÍRTORI, Bruna, ob. cit. y COMISSOLI, Adriano, ob. cit.
} 
de un modo diferente, un vínculo con un liderazgo misionero. Esas diferentes configuraciones convivían en esa época de conquista y de reordenamiento social de la frontera.

Se debe advertir que, en muchas ocasiones, el análisis de las relaciones de compadrazgo se limita a los vínculos de los sujetos en aquella capilla o parroquia. Sin embargo, las invitaciones que las parejas estudiadas hacían a personas ajenas a la localidad para que apadrinaran sus hijos nos recuerda que la actuación de esos agentes tenía un alcance geográfico más amplio. La mayoría de ellos era migrante de las áreas antiguas de Río Grande de San Pedro o de la capitanía de San Pablo. Mantenían relaciones con sus regiones de origen y, principalmente, con las importantes plazas del este de la provincia y con el norte de Uruguay. Una cartografía más amplia de las relaciones de las parejas de la elite exige la búsqueda de otras fuentes, lo que escapa a las posibilidades de este artículo. Eso no invalida el estudio hecho aquí, pero advierte que, cuando se piensa en la forma de las jerarquías locales, es necesario tener en cuenta su carácter abierto.

Finalmente, debemos señalar otro límite de este tipo de análisis. Como vimos, los conjuntos de compadrazgo de las parejas que más frecuentemente eran llamadas a bautizar eran heterogéneos socialmente. No obstante, aunque en esos conjuntos hubiera representación de grupos que podemos llamar de subalternos (esclavos, indios, "pretos", pardos libres, madres solteras), ellos eran siempre minoría, mientras que como madres y padres de bautizados en toda la muestra estudiada eran mayoría. En otros trabajos se ha aislado solamente a aquellos bautizados expresamente designados como "indios" o "guaraníes" y lo mismo se hizo después con los "esclavos". El resultado encontrado es que apenas dos parejas presentes, los padrinos y madrinas más invitados para apadrinar, se repiten aquí. Uno de ellos era la pareja india Vicente Aleixo y Bernardina Flora. Del mismo modo, son raros los padrinos y las madrinas con muchísimos ahijados. Recortamos aquellos que poseían más de cuatro ahijados indios o esclavos y el resultado fue que la mayoría de las parejas presentes se dio dentro de las mismas categorías, indicando una práctica diseminada de compadrazgo horizontal. Aquí es imposible profundizar en la cuestión, pero sirve para dejar clara la existencia de diferentes formas de construcción de alianzas mediante el compadrazgo en un espacio social que era, ciertamente, bastante heterogéneo. 


\section{Consideraciones finales}

El estudio del compadrazgo en las tres parroquias (Paysandú, Belén y Alegrete) confirma la existencia de una vasta zona de frontera multicultural, donde diferentes frentes de expansión colonial se encontraron y después dieron origen a proyectos de soberanía diversos. Allí había contacto e intercambio no solo de bienes, sino también de personas, ideas y alianzas familiares y políticas. Era una región de frontera abierta, donde se desarrollaban procesos de conquistas y migraciones.

Los resultados alcanzados son dispares pues la acumulación de la historiografía sobre el tema para el caso brasileño es mayor a la que estudia el Uruguay. En ese sentido, la indagación en otras fuentes, así como los resultados de investigaciones actualmente en curso, podrán arrojar nueva información sobre el carácter del compadrazgo en esa frontera, sobre todo en lo que tiene que ver con el alcance de ese vínculo, ya sea como generador de beneficios personales, económicos o de cualquier otro tipo.

En el contexto estudiado, la guerra y la posibilidad de redistribuir bienes aparece como importante fuente de prestigio y de estructuración de alianzas de reciprocidad vertical, como se puede percibir por la prominencia de los oficiales militares o milicianos, bien como sus esposas, entre aquellos más frecuentemente invitados a apadrinar. Sin embargo, también percibimos la diversidad de los motivos que generaban una invitación de esa naturaleza. Incluso entre esos padrinos y madrinas frecuentes, los conjuntos de compadres eran socialmente diversos. Como pudimos constatar en el estudio sobre Alegrete, las alianzas que permitían el acceso a importantes recursos materiales e inmateriales en aquel contexto podían ser forjadas con grupos diferentes según los agentes involucrados.

Con la incorporación de nuevas fuentes para el estudio de las alianzas analizadas se podrían abrir cauces en el estudio de la historia política en la frontera y de cómo se organizó la lucha política en las primeras décadas del siglo XIX. En otras palabras, los casos estudiados permiten avanzar sobre las características de la construcción estatal en ese espacio fronterizo. Así lo vimos en algunos casos en Paysandú, cuando en los años en que esos padrinos ocuparon cargos públicos aumentaron la cantidad de ahijados. Resta conocer el "funcionamiento" de ese 
vínculo y sus implicancias más allá de la aceptación del rol por parte de los compadres.

En un espacio fronterizo caracterizado por la misma estructura socioeconómica, aunque disputado por soberanías distintas, el compadrazgo pudo haber sido sinónimo de liderazgo local, vinculando los territorios de un lado y otro y favoreciendo la circulación de mercancías y servicios en zonas con difusos controles centrales.

\section{Fuentes}

Brasil, Arquivo Histórico do Rio Grande do Sul (AHRS), Fundo Autoridades Militares, 23.07.1810, Francisco das Chagas Santos.

Brasil, Archivo de la Diócesis de Uruguaiana (ADU), RS, 1816-1845, Libro de Bautismos Capilla de Alegrete, n.1, n.2, n.3 y Libro de Esclavos.

DE MOUSSY, Martín, “Notas de viaje por el río Uruguay”, Revista Histórica, Tomo LV, año LXXXIV, nº 164-165, Montevideo, diciembre de 1991.

SAINT HILAIRE, Auguste, Al sur del Brasil, al norte del Río de la Plata, Montevideo, Udelar, 2005.

Uruguay, Archivo Curia Eclesiástica de Salto (ACES), Legajos de Bautismos de la Parroquia de Nuestra Señora de Belén.

Uruguay, Archivo General de la Nación (AGN), Ex-Archivo General Administrativo, libro ${ }^{\circ}$ 277, Padrones de Paysandú.

Uruguay, Parroquia San Benito de Paysandú, libro de bautismos $n^{0} 2$.

\section{Bibliografía}

ARAÚJO, Orestes, Diccionario Geográfico del Uruguay, Montevideo, Moderna, 1912.

AZPIROZ PERERA, Andrés Osvaldo, Relaciones de sociabilidad y poder en la frontera del litoral del río Uruguay al norte del río Negro, 180o-1852, Tesis para obtener el título de Magíster en Ciencias Humanas, opción Historia Rioplatense, FHCE, Udelar, Montevideo, febrero 2017.

BARRIOS PINTOS, Aníbal, Paysandú. Historia General, Montevideo, Intendencia Municipal de Paysandú, 1989.

BARRIOS PINTOS, Aníbal, Historia de los Pueblos orientales, Montevideo, Ediciones de la Banda Oriental y Ediciones Cruz del Sur, 2008.

BOIXADÓS, Roxana; FARBERMAN, Judith, "Clasificaciones mestizas. Una aproximación a la diversidad étnica y social en Los Llanos riojanos del siglo XVIII", Judith FARBERMAN y Silvia RATTO (coord.), Historias mestizas en el Tucumán colonial y las pampas (siglos XVII-XIX), Buenos Aires, Editorial Biblos, 2009. 
BRUGGER, Silvia María, "Escolhas de padrinhos e relações de poder: uma análise do compadrio em São João d'El Rey (1736-1850)”, CARVALHO, José Murilo de, Nação e cidadania no Império: novos horizontes, Rio de Janeiro, Civilização Brasileira, 2007, pp. 313-347.

COMISSOLI, Adriano, “"Continuo a ter espias para saber o que mais respirar»: comandos de fronteira e redes de informação na fronteira platina do império português (séc. XIX)”, Revista Ultramares, vol. 5, 2016, pp. 127-159.

DÁVILA, Adriana; AZPIROZ, Andrés, Indios, cautivos y renegados en la frontera. Los blandengues y la fundación de Belén, 180o-1801, Montevideo, Ediciones Cruz del Sur, 2015.

FARINATTI, Luís Augusto.

- "Famílias, relações de reciprocidade e hierarquia social na fronteira meridional do Brasil (1816-1845)", Encontro Estadual de História, 10, Anais eletrônicos Santa Maria, ANPUH-RS - UFSM, 2010. Acceso: http://www.eeh2010.anpuhrs.org.br/site/anaiscomplementares\#L.

- Confins Meridionais: famílias de elite e sociedade agrária no sul do Brasil (18251865), Santa Maria, Editora da UFSM, 2010.

- “A espada e a capela”, História Unisinos, vol. 16, n 3, 2012, pp. 294-306.

- "Gente de todo lado: deslocamentos populacionais, registros de batismo e reordenação social na fronteira meridional (Alegrete 1816-1845)”, Ana Silvia V. SCOTT; José Carlos S. CARDOZO y otros (orgs.), História da Família no Brasil Meridional. Temas e perspectivas, São Leopoldo, Oikos Editora, 2014, pp. 215-238.

- "Padrinhos preferenciais e hierarquia social na fronteira sul do Brasil (1816-1845)", Roberto GUEDES; João L. R. FRAGOSO (orgs.), História social em registros paroquiais (sul-sudeste do Brasil, séculos XVIII e XIX), Rio de Janeiro, Mauad X, 2016, pp. 102-128.

FARINATTI, Luís Augusto; RIBEIRO, Max Roberto P., "Guaranis nas capelas da fronteira: migrações e presença missioneira no Rio Grande de São Pedro (Alegrete e Santa Maria, 1812-1827)", XII Simpósio Internacional HIU. A experiência missioneira: território, cultura e identidade, CD-ROM, 2010.

FARINATTI, Luís Augusto; MATHEUS, Marcelo Santos, "Sobre Angélica, José Maria e Jacinto: hierarquia social e padrinhos/madrinhas preferenciais escravos no sul do Brasil (1817-1845)", Maíra Ines VENDRAME; Alexander KARSBURG y otros (orgs.), Micro-história, trajetórias e imigraçāo, Sāo Leopoldo, Oikos, 2015, pp. 99-121.

FARINATTI, Luís Augusto; VARGAS, Jonas M., "Elites regionais, guerra e compadrio: a família Ribeiro de Almeida e suas redes de relações (Rio Grande do Sul, 1816-1844)", Topoi (Online): revista de História, vol. 15, 2014, pp. 389-413.

FERNÁNDEZ SALDAÑA, José María, Diccionario Uruguayo de biografías 18101940, Montevideo, Adolfo Linardi, 1945.

FRAGOSO, João Luis Ribeiro, “A nobreza vive em bandos: a economia política das melhores famílias da terra do Rio de Janeiro, século XVII. Algumas notas de pesquisa”, Tempo, vol. 8, n⿳0 15, UFF, Niterói, julio-diciembre 2003, pp. 11-36. 
GARAVAGLIA, Juan Carlos, San Antonio de Areco, 168o- 188o. Un pueblo de la campaña, del Antiguo Régimen a la modernidad argentina, Buenos Aires, Prohistoria Ediciones, 2009.

GONZÁLEZ BERNALDO DE QUIRÓS, Pilar, “La ‘sociabilidad' y la historia política”, Nuevo mundo. Mundos nuevos [en línea], 17 de febrero de 2008. Disponible en https://nuevomundo.revues.org/24082\#tocto1n1

GUEDES, Roberto, Egressos do cativeiro. Trabalho, família, aliança e mobilidade social (Porto Feliz, São Paulo, c. 1789-c.1850), Rio de Janeiro, MauadFAPERJ, 2008.

HAMEISTER, Martha, Para Dar Calor à Nova Povoação: estudo sobre estratégias sociais e familiares a partir dos registros batismais da Vila do Rio Grande (1738-1863), Tese (doutorado em História Social), Instituto de Filosofia e Ciências Humanas, UFRJ, Rio de Janeiro, 2006.

HAMEISTER, Martha; GIL, Thiago. "Fazer-se elite no extremo-sul do Estado do Brasil: uma obra em três movimentos: continente do Rio Grande de São Pedro (século XVIII)”, João Luis Ribeiro FRAGOSO; Antonio Carlos Jucá SAMPAIO y Carla Maria Carvalho ALMEIDA (orgs.), Conquistadores e negociantes: história de elites no Antigo Regime nos Trópicos. América Lusa, séculos XVI a XVIII, Rio de Janeiro, Civilização Brasileira, 2007, pp. 265-310.

KUHN, Fabio, Gente da Fronteira: família, sociedade e poder no sul da América Portuguesa - Século XVIII, Tese (doutorado em História), UFF, Niterói, 2006.

MACHADO, Cacilda da Silva.

- A trama das vontades: negros, pardos e brancos na construção da hierarquia social do Brasil escravista, Rio de Janeiro, Apicuri, 2008.

- "O Capitão João Pereira de Lemos e a parda Maria Sampaio: notas sobre as hierarquias rurais costumeiras no Rio de Janeiro do século XVIII”, Monica Ribeiro OLIVEIRA; Carla María ALMEIDA (orgs.), Exercícios de microhistória, Rio de Janeiro, FGV Editora, 2009.

MATEO, José, Población, parentesco y red social en la frontera. Lobos (provincia de Buenos Aires) en el siglo XIX, Mar del Plata, Universidad Nacional de Mar del Plata, 2001.

OSÓRIO, Helen, Apropriação da Terra no Rio Grande de São Pedro e a formação do espaço platino. Dissertação (mestrado em História), UFRGS, Porto Alegre, 1990.

RIBEIRO, Max, Estratégias indígenas na fronteira meridional: os guaranís missioneiros após a conquista lusitana (Rio Grande de Sāo Pedro 1801-1834), Porto Alegre, Dissertação (mestrado em História), UFRGS, 2013.

SANTILLI, Daniel.

- "Representación gráfica de redes sociales. Un método de obtención y un ejemplo histórico", Mundo Agrario, vol. III, nº 6, primer semestre de 2003.

- "Entre el clientelismo y el reforzamiento de vínculos. Familia y padrinazgo en Buenos Aires, 1780-1840", Revista de Demografía Histórica, vol. 27, ${ }^{\circ} 2$, 2009, pp. 111-148. 
SCHULKIN, Augusto, Historia de Paysandú. Diccionario biográfico, Buenos Aires, Editorial Von Roosen, 1958, tres tomos.

SIRTORI, Bruna, Entre a cruz, a espada, a senzala e a aldeia: hierarquias sociais em uma área periférica do Antigo Regime (1765-1784), Dissertação (mestrado em História Social), Instituto de Filosofia e Ciências Humanas, UFRJ, Rio de Janeiro, 2007.

VENÂNCIO, Renato Pinto; SOUZA, María José Ferro; PEREIRA, María Teresa Gonçalves, "O compadre governador. Redes de compadrio em Vila Rica em fins do século XVIII”, Revista Brasileira de História, vol. 26, $\mathrm{n}^{\circ}$ 52, 2006, pp. 273-294.

XAVIER, Angela Barreto; HESPANHA, António Manuel. "A representação da sociedade e do poder”, José MATTOSO (org.), História de Portugal - vol. 4. O Antigo Regime, Lisboa, Editorial Estampa, 1998, pp. 120-155. 